\title{
СПЕКТРОФОТОМЕТРИЧЕСКОЕ ИССЛЕДОВАНИЕ КОМПЛЕКСООБРАЗОВАНИЯ МАГНИЯ (І) С РЯДОМ АМИНОКИСЛОТ В ВОДНЫХ РАСТВОРАХ
}

\author{
И.А. Томашевский, О.А. Голованова, С. В. Анисина \\ ИВАН АЛЕКСАНДРОВИЧ ТОМАШЕВСКИЙ - кафедра неорганической химииОмского государственного \\ университета им.Ф.М. Достоевского.E-mail: ivan_tomashevsky@mail.ru. \\ ОЛЬГА АЛЕКСАНДРОВНА ГОЛОВАНОВА - профессор, доктор геолого-минералогических наук, заведу- \\ ющчий кафедрой неорганической химии Омского государственного университета им. Ф.М. Достоевского. \\ Область научных интересов: минералогия, кристаллохимия, прикладная экология, патогенноеминералоо- \\ бразованиев организме человека.E-mail: golovanoa2000@mail.ru.
}

СВЕТЛАНА ВЛАДИСЛАВОВНА АНИСИНА - кафедра неорганической химииОмского государственного университета им.Ф.М. Достоевского.E-mail: svetik.ledi.97@mail.ru.

Омский государственный университет им. Ф.М. Достоевского, пр. Мира 55, Омск, Российская Федераџия, 644077.

В работе проведено спектрофотометрическое исследование комплексообразованиямагния (II) с глицином, L-аспарагиновой и L-глутаминовой кислотами в водном растворе при 298, 15 K. Метод основывается на снятии спектров смесей магния (II) и аминокислот различной кониентрации с их дальнейшей обработкой методом множественной линейной регрессии (МЛР). Для растворов было произведено определение оптической плотности в широком интервале длин волн: 190370 нм, и далее, с помощью специального программного обеспечения (DefMix, KOEFF_COUNTER, CONCENTR_COUNTER), были выбраны длины волн, по которым определение равновесных концентраџий участников реакиии проходит с наименьщей относительной ошибкой определения. Для каждого комплекса были выбраны те длины волн, по которым относительная ошибка определения составляла менее 5 \%. По данным длинам волн были рассчитаныобщчие константы устойчивости комплексов и энергия Гиббса комплексообразования. Приведены отличия в полученных значениях констант устойчивости комплексов аминокислот с магнием (II) и установлень факторы, влияющие на их устойчивость. Для системы «магний - глутаминовая кислота» $\lg$ составил 2,02, а энергия Гиббса комплексообразования 11,51 кДж/моль, для системы «магний-аспарагиновая кислота» эти значения составили 2,61 и 14,87 кДж/моль, для системьи «магний - глицин» 3,59 и 20,05 кДж/моль. Выполнение такой работь позволит расширить базу данных о взаимодействии магния (II) с аминокислотами. Полученные результаты могут быть использованы при исследованиях различных процессов биоминералообразования в организме человека, а также при создании медицинских препаратов, направленньх на точечное воздействие.

Ключевые слова: аминокислоты, спектрофотометрия, ионы магния, константы комплексообразования. 


\title{
SPECTROPHOTOMETRIC STUDY OF THE COMPLEXATION OF MAGNESIUM (II) WITH A NUMBER OF AMINO ACIDS IN AN AQUEOUS SOLUTIONS
}

\author{
I.A. Tomashevskiy, O.A. Golovanova, S. V. Anisina \\ Department of Inorganic Chemistry, Omsk State University F.M. Dostoevsky, Mira Ave. 55, Omsk, Russian \\ Federation, 644077.
}

\begin{abstract}
In this article, a spectrophotometric study of the complexation of magnesium (II) with glycine, L-aspartic and Lglutamic amino acids in an aqueous solution at 298,15 K is held. The method is based on taking spectra of mixtures of magnesium (II) and amino acids of various concentrations with their further processing by the method of multiple linear regression (MLR). For work solutions, the optical density was determined in a wide range of wavelengths: 190-370 nm, and then, using special software (DefMix, KOEFF_COUNTER, CONCENTR_COUNTER), the wavelengths were chosen to determine the equilibrium concentrations of the reaction participants with the smallest relative determination errors. For each complex, those wavelengths were selected for which the relative determination errors were less than 5\%. Using these wavelengths, the overall stability constants of the complexes and the Gibbs energy of complexation were calculated. Differences in the obtained values of the stability constants of complexes of amino acids with magnesium (II) are explained and factors affecting their stability are established. For the magnesium - glutamic acid system, lgK was 2,02, and the Gibbs energy of complexation was -11,51 kJ/mol, for the magnesium-aspartic acid system, these values were 2,61 and-14,87 kJ/mol, for the system "magnesium glycine" 3,59 and-20,05 kJ/mol. Performing this work will expand the database on the interaction of magnesium (II) with amino acids. The results can be used in studies of various processes of biomineral formation in the human body, as well as in the creation of medications aimed at targeted exposure.
\end{abstract}

Keywords: amino acids, spectrophotometry, magnesium ions, complexation constants.

\section{Введение}

Известно, что аспарагиновая (HAsp \pm ) и глутаминовая (HGlu \pm ) кислоты являются фундаментальными дикарбоновыми аминокислотами, участвующие в построении белков и пептидов, а также интеграции азотистого обмена в организме и обменом липидов и углеводов.

По своей структурной формуле аспарагиновая кислота очень близка к глутаминовой, отличаясь от нее лишь одной группой $\mathrm{CH}_{2}$. Она участвует в орнитиновом цикле мочевинообразования, в реакциях трансаминирования углеводов. Глутаминовая кислота также включается в синтез ряда специфических метаболитов, в частности глутатиона и глутамина.

Глицин (HGly \pm ) является простейшей алифатической аминокислотой. Она является регулятором обмена веществ, нормализует и активирует процессы торможения в центральной нервной системе организма человека, снижает психоэмоциональное напряжение, повышает умственную работоспособность [1].
В отличие от комплексообразования ионов тяжелых металлов с аминокислотами, которое подробно изучено и нашло применение в медицине [28], а также кальция (II) с аминокислотами, по которому исследования ведутся [9-11], процессы комплексообразования выше перечисленных аминокислот с магнием (II) исследованы недостаточно. В современной литературе чаще всего представлены работы по реакциям комплексообразования магния (II) одновременно с двумя или более лигандами. Например, в работе [12] методом математического моделирования химических

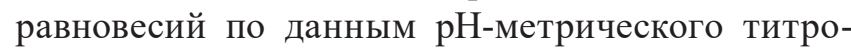
вания изучены химические равновесия в разбавленных водных растворах, содержащих высокомолекулярный гепарин $\left(\mathrm{Na}_{4} \mathrm{Hep}\right)$ и глицин (HGly), а также в растворах системы $\mathrm{MCl}_{2}-\mathrm{Na}_{4} \mathrm{Hep}-\mathrm{HGly}-$ $\mathrm{H}_{2} \mathrm{O}-\mathrm{NaCl}\left(\mathrm{M}=\mathrm{Ca}^{2+}, \mathrm{Mg}^{2+}\right)$ на фоне $0,15 \mathrm{M} \mathrm{NaCl}$ при температуре $37{ }^{\circ} \mathrm{C}$. Авторы установили, что ионы $\mathrm{Ca}^{2+}$ и $\mathrm{Mg}^{2+}$ образуют с гепарином и глицином устойчивые протонированные смешанолигандные комплексы состава, их константы образования на порядок превосходят константы 
образования однотипных форм кальция и магния с гепарином.

Целью данной работы являетсярасчет термодинамических констант устойчивости комплексных соединений ионов магния (II) с глицином, L-аспарагиновой и L-глутаминовой кислотами и объяснение различия в значениях констант.

\section{Методика эксперимента}

Для достижения поставленной цели были приготовлены и спектрофотометрически исследованы водные растворы магния (II) и аминокислот (глицин, L-аспарагиновая и L глутаминовая). При приготовлении растворов были использованы кристаллические формы АК фирмы Омскреактивквалификации «х.ч.». Препараты хранили в эксикаторе над оксидом фосфора (V).

Раствор $\mathrm{Mg}\left(\mathrm{NO}_{3}\right)_{2}$ квалификации «х.Ч.» $(\mathrm{C}=0,1000$ моль/л) готовили путем растворения кристаллического $\mathrm{Mg}\left(\mathrm{NO}_{3}\right)_{2} \cdot 6 \mathrm{H}_{2} \mathrm{O}$ в бидистилляте. Концентрацию устанавливали комплексонометрическим методом [13].

Концентрации компонентов в водных смесях были выбраны, исходя из достижения необходимого (отличной от фонового в 4 или более раз) уровня оптической плотности соответствующих спектров. Были приготовлены рабочие растворы с концентрациями компонентов растворов, представленными в Табл. 1.

Таблица 1

\section{Концентрации компонентов рабочих смесей}

\begin{tabular}{ccc}
\hline Смесь & $\mathbf{C}\left(\mathbf{M g C l}_{2}\right)$, моль/л & $\mathbf{C ( а к - т ы ) , ~ м о л ь / л ~}$ \\
\hline 1 & 0,0100 & 0,00001 \\
2 & 0,0500 & 0,0005 \\
3 & 0,0010 & 0,0001 \\
4 & 0,0050 & 0,0050 \\
5 & 0,0001 & 0,0010 \\
6 & 0,0005 & 0,0500 \\
7 & 0,00001 & 0,0100 \\
\hline
\end{tabular}

Обзорные спектры регистрировали на спектрофотометре ПЭ-5400УФ в диапазоне длин волн 190370 нм (холостой раствор - бидистиллированная вода) в кювете с толщиной светопоглощающего слоя $1=1,0$ см.

Поскольку взаимодействие ионов магния (II) с аминокислотами не так ярко выражено, как комплексообразование d-элементов с аминокислотами, необходимо увеличение чувствительности и селективности используемого метода спектрофо- тометрического анализа. Для этого, полученные спектры обрабатывали с использованием хемометрических методов математической обработки данных. Основным методом, применяемым для обработки данных спектрофотометрического анализа, является метод множественной линейной регрессии (МЛР). Работы с использованием этого метода ранее проводились на более изученных с точки зрения природы аналита объектах [1418].

В случае применения метода МЛР содержания компонентов в модельных смесях вычисляют, решая сильно переопределенную систему линейных уравнений вида:

$$
\mathrm{A}_{\mathrm{x}}=\mathrm{K}^{*} \mathrm{C}_{\mathrm{x}}
$$

где $\mathrm{A}_{\mathrm{x}}$ - вектор оптических плотностей анализируемой смеси при $\mathrm{n}$ длинах волн, $\mathrm{K}^{*}$ - матрица коэффициентов светопоглощения размера $\mathrm{n}$ $\mathrm{x}$ p (p-число определяемых компонентов, $\mathrm{n}>\mathrm{p}$ ), $\mathrm{C}_{\mathrm{x}}$ - вектор концентраций компонентов анализируемой смеси. В основе вычислений лежит метод наименьших квадратов (МНК).

Решение системы (1) в рамках МНК находят как:

$$
\mathrm{C}_{\mathrm{x}}=\left(\mathrm{K}^{*} \mathrm{~T} \mathrm{~K}^{*}\right)^{-1} \mathrm{~A}_{\mathrm{x}}
$$

По найденным концентрациям всех участников комплексообразования рассчитываются общие константы устойчивости [19]. При решении этой задачи метод МЛР предполагает пересчет всех возможных частиц на частицы одного типа. Поскольку АК являются стерически объемными лигандами и их координирование с ионами магния при подходе сразу нескольких молекул затруднен, поэтому при расчете и обсуждение результатов учитывается состав комплексов $1: 1$.

\section{Результаты и их обсуждение}

Ниже в качестве примера приведен набор спектров (Рис. 1), снятых для соответствующих рабочих растворов смесей ионов магния (II) и аспарагиновой кислоты. Указано поглощение только для тех длин волн (по оси абсцисс), по которым оптическая плотность (по оси ординат) значимо отличается от нуля.

Сравнение же спектров смесей ионов магния (II) с аспарагиновой и глутаминовой кислотами показало, что спектры являются очень похожими, но не являются одинаковыми за счет различия в одной группе $\mathrm{CH}_{2}$ в структуре аминокислоты.

Для того, чтобы установить раздельное влияние наличия в растворе ионов магния и аминокис- 


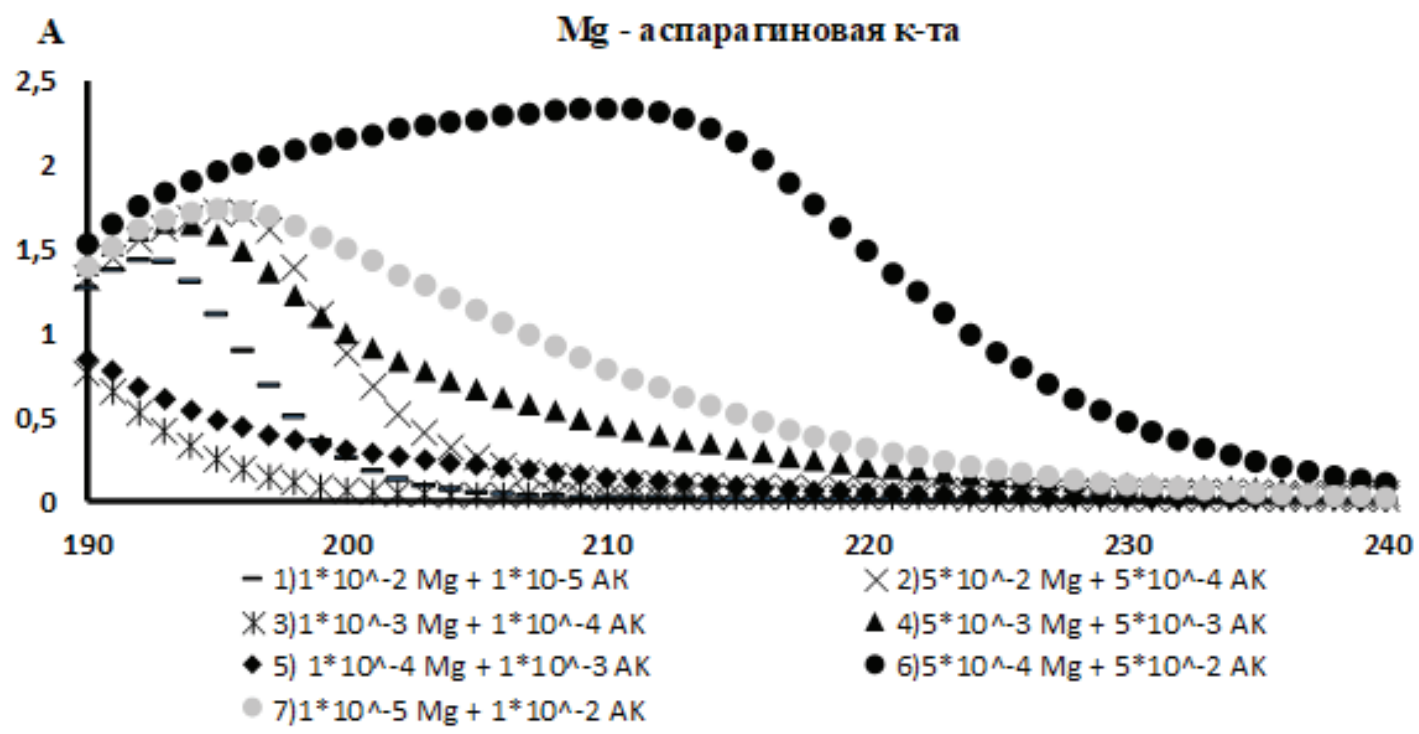

Рис 1. Спектры поглощения для рабочих растворов смесей ионов магния (II) с аспарагиновой кислотой

Таблица 2 лоты на оптическую плотность, были приготовле-

Концентрации ионов магния (II) и глицина для приготовления дополнительных рабочих смесей

\begin{tabular}{ccc}
\hline Смесь & $\mathbf{C}\left(\mathbf{M g C l}_{2}\right)$,моль/л & С(глицин), моль/л \\
\hline 8 & 0,0100 & 0,0010 \\
9 & 0,0100 & 0,0001 \\
10 & 0,0010 & 0,0100 \\
11 & 0,0001 & 0,0100 \\
\hline
\end{tabular}
ны дополнительные рабочие растворы (Табл. 2)

Полученные спектры дополнительных рабочих растворов выглядят следующим образом (рис. 2).

Как видно из спектров, и наличие в растворе ионов магния, и наличие аминокислоты, вносят свой вклад в изменение оптической плотности приготовленных смесей. Этот вклад может быть небольшим, но с учетом того, что в растворе происходит образование комплекса магния (II) и аминокислоты, даже небольшой вклад каждого из участ-

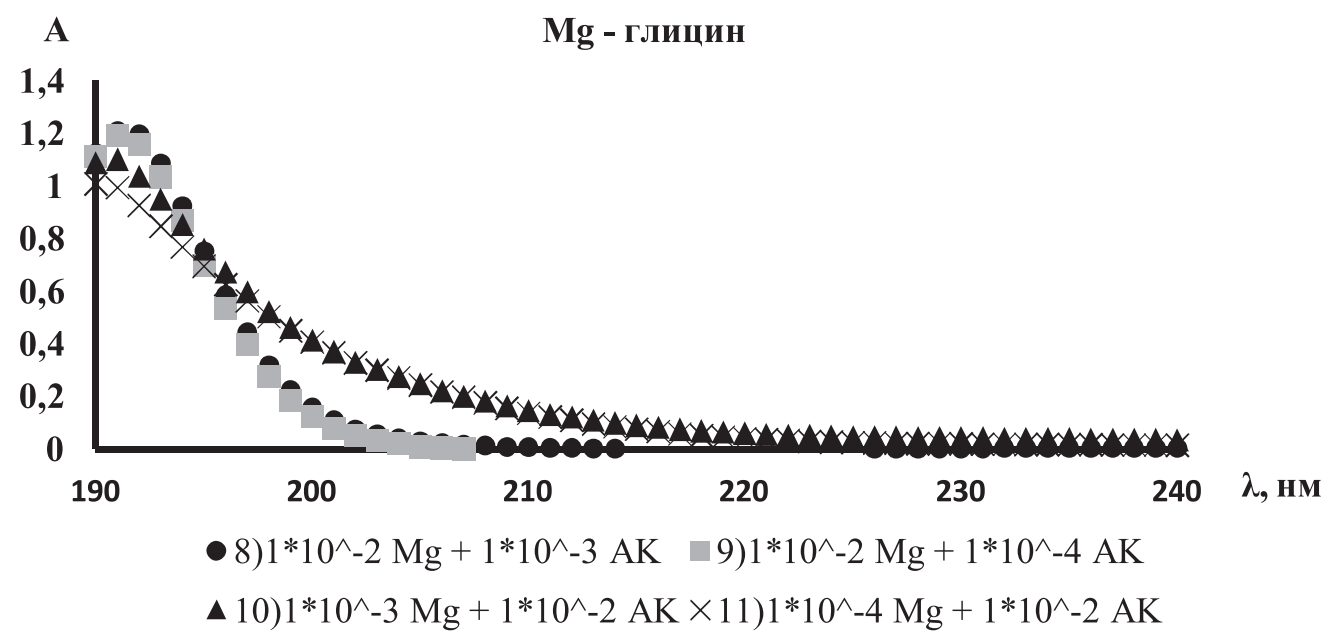

Рис 2. Спектры поглощения для дополнительных рабочих растворов смесей ионов магния (II) с глицином 
ников реакции может влиять на суммарную оптическую плотность на отдельных длинах волн с учетом неаддитивности смесей, что косвенно указывает на возможность определения констант устойчивости методом МЛР, поскольку он способен оперировать данными вне зависимости от уровня выраженности сигнала.

Первоначально, для применения метода МЛР, необходимо рассчитать предварительные коэффициенты молярного светопоглощения для всех участников реакции. Для этого необходимо знать примерный порядок значения константы, для этого были использованы значения из работы [20]. Зная эти примерные значения общих констант устойчивости исследуемых комплексов и общие концентрации каждого компонента, с помощью специального программного обеспечения (DefMix, KOEFF_ COUNTER, CONCENTR_COUNTER) по методу МЛР были рассчитаны предварительные равновесные концентрации каждого участника комплексообразования. Далее, зная равновесные концентрации для каждого рабочего раствора и соответствующие значения оптической плотности для каждого из них, были рассчитаны коэффициенты молярного светопоглощения $\left(\varepsilon, л^{\cdot}\right.$ моль $\left.^{-1} \cdot \mathrm{cm}^{-1}\right)$ для всех участников реакции. В качестве примера, на рис. 3 приведены молярные коэффициенты светопоглощения $\varepsilon$ для участников реакции комплексообразования между магнием (II) и глицином.

Основным критерием возможности использования этих коэффициентов при дальнейших расчетах является корректность их значений. Например, если при $\lg \mathrm{K}=4$ значение молярного коэффициента светопоглощения одного или нескольких участников реакции значимо (статистически отличается от погрешности определения этим методом) ниже нуля, то выбранное начальное значение кон- станты для расчета равновесных концентраций некорректно (занижено) и его нужно увеличить. Противоположная ситуация может заключаться в том, если при $\lg \mathrm{K}=4$ значения коэффициентов одного из участников реакции очень велики и явно не соответствуют природе данных веществ и/или известным справочным значениям. В таком случае выбранное значение константы для расчета равновесных концентраций некорректно завышено и его нужно уменьшить, пересчитав равновесные концентрации при более низком значении константы и повторив пересчет в программном обеспечении.

Полученные молярные коэффициенты участников реакций в заданном диапазоне длин волн значимо отличаются от нуля, причем молярные коэффициенты ионов магния (II) и АК во всех случаях имеют значения одного порядка, а поглощение комплексных соединений различается между собой и зависит от природы взаимодействия ионов магния и АК, а также от строения аминокислот.

По рассчитанным коэффициентам молярного поглощения $\varepsilon$ и фактическим спектрам поглощения смесей были рассчитаны истинные равновесные концентрации каждого участника реакции комплексообразования всех рабочих смесей. На этом этапе программа корректирует значение константы, поскольку идет перебор значений относительно оптической плотности спектров и молярных коэффициентов всех участников реакции на каждой длине волны исследуемого диапазона. Рассчитанную общую концентрацию комплекса можно найти путем суммирования найденной истинной равновесной концентрации магния (II) и истинной равновесной концентрации комплекca, после чего от рассчитанной общей концентрации ионов магния вычитается известная исходная концентрация ионов магния, полученная разница

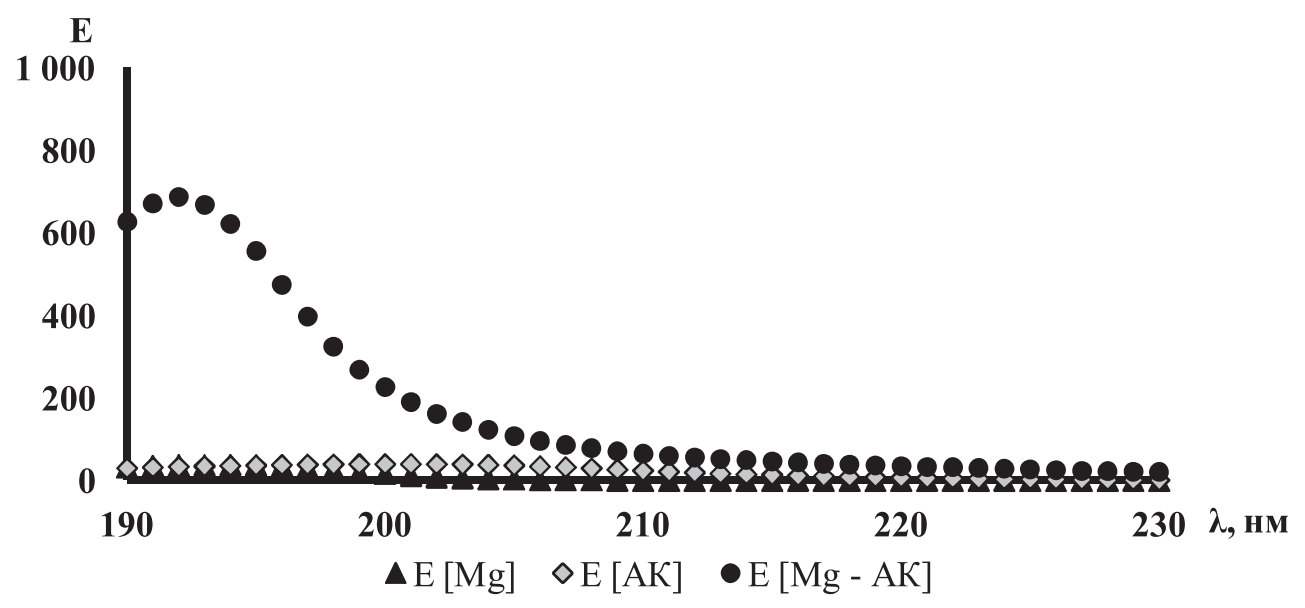

Рис. 3. Молярные коэффициенты светопоглощения Е для участников реакции комплексообразования между ионами магния (II) и глицином 
делится на исходную концентрацию и умножается на $100 \%$. Полученное значение является относительной ошибкой определения суммарной (равновесной концентрации свободных ионов магния (II) + равновесной концентрации магния (II) в составе комплекса) концентрации магния (II) в растворе. Аналогичная ошибка рассчитывается и по аминокислоте.

Таким образом, сводится баланс найденных концентраций и сравнивается с тем, что было введено изначально в рабочие растворы. Задача стоит в подборе такой смеси, в которой относительная ошибка определения конечной общей константы будет минимальной [19]. Чтобы снизить значение относительной ошибки, необходимо сделать оптимальный выбор длин волн, молярные коэффициенты поглощения и оптической плотности которых будут принимать участие в расчете истинных равновесных концентраций участников комплексообразования. Иными словами, необходимо не принимать в расчет истинных равновесных концентраций диапазоны длин волн, где коэффициенты молярного поглощения либо выражены недостаточно хорошо, либо где дифференциация молярных коэффициентов аминокислоты и комплекса друг относительно друг друга невелика. Путем подбора интервалов этих длин волн, наименьшую относительную ошибку для комплекса в системе " $\mathrm{Mg}^{2+} \mathrm{Asp}$ " демонстрирует диапазон длин волн 190-220 нм, для системы " $\mathrm{Mg}^{2+} \mathrm{Gly"} \mathrm{-} \mathrm{диапазон} \mathrm{длин} \mathrm{волн} 195$ 210 нм, для “" $\mathrm{Mg}^{2+} \mathrm{Glu}$ ” - 195-200 нм.

По этим условиям были определены равновесные концентрациивсех участников комплексообразования и рассчитаны соответствующие $\lg \mathrm{K}$ для данных трех систем и относительные ошибки определения для каждой из них. Наименьшая ошибка расчета общих констант для всех систем выявлена для рабочих растворов, в которых концентрации комплексообразователя и лиганда соотносятся как 1:1, то есть для смеси № 4 из Табл. 1. Также, для вышеуказанных комплексов по формуле (3) была рассчитана энергия Гиббса комплексообразования:

$$
\Delta \mathrm{G}_{298}{ }^{\mathrm{o}}=-\mathrm{RT} \ln \mathrm{k}_{\mathrm{p}}
$$

В Табл. 3 приведены рассчитанные для комплексов $\operatorname{lgK}$, их относительные ошибки определения и энергии Гиббса комплексообразования.

Как видно, устойчивость комплексов ионов магния с глицином выше, чем с бикарбоновыми аминокислотами. Это объясняется тем, что подход ионов комплексообразователя к этой аминокислоте не затруднен - нет объемных заместителей в структуре аминокислоты, а углеродный скелет амино-
Таблича 3

Рассчитанные $\operatorname{lgK}$ и их относительные ошибки определения для систем " $\mathrm{Mg}^{2+}$ аминокислота"

\begin{tabular}{|c|c|c|c|}
\hline $\begin{array}{c}\text { Аминокислота } \\
\text { в составе } \\
\text { комплекса }\end{array}$ & $\lg K$ & $\varepsilon, \%$ & $\begin{array}{c}\Delta \mathrm{G}_{298}{ }^{\circ}, \\
\text { кДж/моль }\end{array}$ \\
\hline Glu & 2,02 & 4,8 & $-11,51$ \\
\hline Asp & 2,61 & 4,5 & $-14,87$ \\
\hline Gly & 3,59 & 5,0 & $-20,05$ \\
\hline
\end{tabular}

кислоты состоит из минимально возможного количества атомов углерода. Соответственно в данном случае, стерический фактор имеет определяющую роль при формировании устойчивых комплексов магния (II) с аминокислотами - несмотря на вторую карбоксильную группу, дающую дополнительную электронную плотность, общая константа устойчивости выше, чем у бикарбоновых кислот. В свою очередь, координационное соединение $\mathrm{Mg}^{2+}$ с аспарагиновой кислотой устойчивее, чем с глутаминовой, поскольку в структуре последней на один атом углерода больше, и молекула глутаминовой кислоты имеет конформацию, в которой две карбоксильные группы подходят к другу на более близкое расстояние, поэтому стерических препятствий возникает больше, чем с аспарагиновой кислотой.

Полученные результаты могут быть использованы в исследованиях физиогенных и патогенных процессов организма человека, протекающих с участием магния (II) и аминокислот, а также при создании медицинских препаратов, направленных на точечное воздействие в организме человека. В перспективе данная работа позволяет создать отдельную базу данных общих констант устойчивости координационных соединений органических лигандов с магнием (II).

\section{Лuтература}

1. Майстер A. Биохимия аминокислот / Под ред. и с предисл.: А.Е. Браунштейн; - М.: Иностр. лит. $1961.530 \mathrm{c}$.

2. Peyrot V., Briand C., Codaccioni F., Sari J.C.ChemicoBiological Interactions. 1987. V. 61. Is. 2. P. 151-158.

3. Mironov V.F., Berliner E.M., Gar T.K.Russ. J. Gen. Chem. (Engl. Trans1.). 1967. N. 37.P. 911-912.

4. Сейфуллина И.И., Мариинко Е.Э., Чебаненко Е.А. Вестник Одесского национального университета, химия. 2013. Т. 18. С. 1(45).

5. Киселёв Ю.М., Добрынина Н.А. Химия координационных соединений./ Л.: Академия. 2007. 343 с.

6. Боцююрко В.И. Врачебное дело. 1977. Т. 2. С. 50-52.

7. Корман Д.Б., Островская Л.А., Кузьмин В.А. Вопросы онкологии.2018. Т. 64. Вып. 6. 
8. Гургенидзе Г., Лабарткава Д., Микаберидзе М., Урушадзе Н., Чоговадзе М. Аллергология и иммунология. 2010. Т. 11. Вып. 2.

9. Курочкин В.Ю. Дисс. «Термодинамика процессов комплексообразования ионов кальция с аминокислотами в водном растворе» канд. хим. наук. М.: Иванов.государственный химико-технологическийун-т. 2011. $121 \mathrm{c}$.

10. Khalil M., Attia A.J. Chem. Eng. Data. 2000. V. 45. Is 45. P. 1108-1111.

11. Golovanova O.A., Tomashevskiy I.A.Russian Journal of Physical Chemistry. 2019. V. 93. № 1. P. 7-17.

12. Николаева Л.С., Семенов А.Н., Бурова Л.И. Журнал неорганической химии. 2011. Том 56. Вып. 4. С. 689-696.

13. Аналитическая химия. Лабораторный практикум / Под ред. Васильева В.П. М.: Дрофа. 2004. 416 с.

14. Власова И.В., Шелпакова А.С., Добровольский С.М., Фисенко А.В. Аналитика и контроль.2009. Том 13. Вып. 3

15. Томашевский И.А., Спиридонова К.С. Спектрофотометрическое определение ионов тяжелых металлов в питьевой воде с применением метода ПЛС-1 Мо- лодежь третьего тысячелетия: XXXVIII региональная студенческая научно-практическая конференция. 2014. С. 270-271.

16. Бурюкина П.А., Власова И.В., Спиридонова К.А. Аналитика и контроль.2013. Т. 17. Вып. 3.

17. Власова И.В., Томашевский И.А., Клишева Г.И., Мановская А.О., Егошина А.Е. Применение спектрофотометрического метода и ик-спектроскопии к анализу лекарственных препаратов по собственному поглощению активных веществ с применением хемометрических алгоритмов. Материалы 5-й международной научно-технической конференции «Техника и технология нефтехимического и нефтегазового производства». 2015. С. 124.

18. Бурюкина П.А., Власова И.В., Миргалеева Р.Р. Вестник Омского университета. 2016. Вып. 3. C. 54-58.

19. Esbensen K. Multivariate Data Analysis: In Practice: an Introduction to Multivariate Data Analysis and Experimental Design. L.: CAMO. 150 p.

20. Martell A.E. Science of The Total Environment. 1987. V. 64. Is. 1-2. P. 125-147 (use of the updated base of constants). https://doi.org/10.1016/0048-9697(87)90127-6 